Micromachines 2011, 2, 410-430; doi:10.3390/mi2040410

OPEN ACCESS

micromachines

ISSN 2072-666X

www.mdpi.com/journal/micromachines

Article

\title{
Development of a Microelectromechanical System (MEMS)-Based Multisensor Platform for Environmental Monitoring
}

\author{
Mathieu Hautefeuille ${ }^{1}$, Brendan O'Flynn ${ }^{2,3}$, Frank H. Peters ${ }^{1,4}$ and Conor O’Mahony ${ }^{2, *}$ \\ 1 Centre for Telecommunications Value-Chain Research, Tyndall National Institute, \\ University College Cork, Cork, Ireland \\ 2 Tyndall National Institute, University College Cork, Cork, Ireland \\ 3 Clarity Centre for Sensor Web Technologies, Cork, Ireland \\ 4 Department of Physics, University College Cork, Cork, Ireland
}

* Author to whom correspondence should be addressed; E-Mail: conor.omahony@tyndall.ie; Tel.: +353-21-490-4200; Fax: +353-21-427-0271.

Received: 15 September 2011; in revised form: 28 October 2011 / Accepted: 29 October 2011 / Published: 3 November 2011

\begin{abstract}
Recent progress in data processing, communications and electronics miniaturization is now enabling the development of low-cost wireless sensor networks (WSN), which consist of spatially distributed autonomous sensor modules that collaborate to monitor real-time environmental conditions unobtrusively and with appropriate levels of spatial and temporal granularity. Recent and future applications of this technology range from preventative maintenance and quality control to environmental modelling and failure analysis. In order to fabricate these low-cost, low-power reliable monitoring platforms, it is necessary to improve the level of sensor integration available today. This paper outlines the microfabrication and characterization results of a multifunctional multisensor unit. An existing fabrication process for Complementary Metal Oxide Semiconductor CMOS-compatible microelectromechanical systems (MEMS) structures has been modified and extended to manufacture temperature, relative humidity, corrosion, gas thermal conductivity, and gas flow velocity sensors on a single silicon substrate. A dedicated signal conditioning circuit layer has been built around this MEMS multisensor die for integration on an existing low-power WSN module. The final unit enables accurate readings and cross-sensitivity compensation thanks to a combination of simultaneous readings from multiple sensors. Real-time communication to the outside world is ensured via
\end{abstract}


radio-frequency protocols, and data collection in a serial memory is also made possible for diagnostics applications.

Keywords: MEMS; microsensors; reliability; cross-correlation; wireless sensor network; telecommunications

\section{Introduction}

The distribution of embeddable, wireless, multisensor modules creates a network that can continually detect and record environmental stresses in the surrounding ambient. Such networks, generally referred to as wireless sensor networks (WSNs) are finding applications in areas that require deployments of a large number of sensor and actuator nodes to monitor environmental stresses in real time in order to detect potential failures and localized anomalies, in areas such as agriculture, telecommunications, building energy management and supply chain management [1-4]. In order to unobtrusively embed wireless sensors within everyday objects, it is important that WSN hardware becomes cheaper, further miniaturized and features reduced power consumption.

In order to develop a sensor platform that helps improve reliability analysis and environmental monitoring techniques, systems of predictive quality control will focus on performance behaviour and environmental conditions on a continuous, real-time basis, so as to identify possible failures at an early stage. Wireless sensors, often referred to as "nodes" or "motes" [1] are attractive for this purpose because of their small size, low power consumption, and potentially low cost of fabrication. They are also easy to interrogate, and communication between units is used to build up a network that gathers all the information needed in real time and either transmits or stores it for later use if connected to a memory [2-4]. Depending on the target application, sensors can be interfaced with a range of wired or wireless communications interfaces as required. An example of such a wireless node is the modular, programmable transceiver-based system presented in Figure 1 that has been designed to fit in a $25 \mathrm{~mm}$ footprint: the Tyndall25 node [3].

Figure 1. $25 \mathrm{~mm}$ module [3] (a) and $10 \mathrm{~mm}$ cube [5] (b) currently under development. The small-scale nature of the $10 \mathrm{~mm}$ module shows that increased sensor integration is vital.

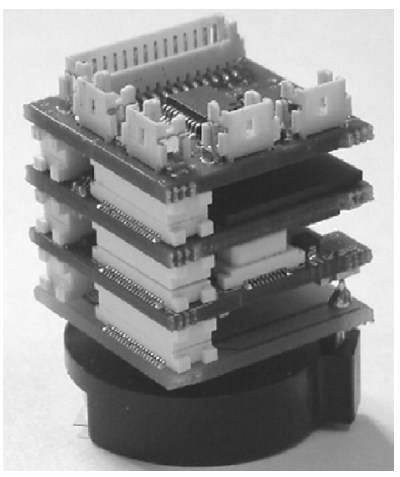

(a)

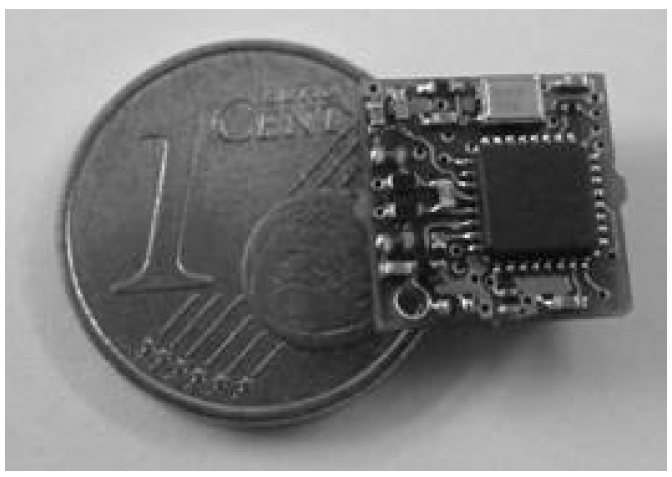

(b) 
Microelectromechanical systems (MEMS) could make a substantial contribution towards the miniaturization of wireless sensor nodes because of their small size, multifunctional capability and low manufacturing costs. The fabrication of multiple MEMS sensors on a single substrate could also result in the implementation of sensor redundancy, thereby enabling higher levels of integration and reliability. In the context of Health and Usage Monitoring Microsystems (HUMMs) in particular, MEMS sensors present numerous advantages [6]. For all these reasons, MEMS-based sensor technology is a fast growing area with a promising future in a wide range of applications [7], as it presents many advantages such as the ability to correct cross-sensitivities and the possibility of deployment of the resulting chip in a larger modular system where sensed data can either be logged or immediately read. A low-power, CMOS compatible, on-demand multisensor MEMS solution is often required in WSN applications. For reasons of cost and size, it is also preferable to integrate all sensors on one single substrate, on top of CMOS circuitry, in a monolithic fashion.

This paper outlines the use of a new fabrication process combining surface and bulk micromachining techniques to fabricate a MEMS-based multifunctional environmental monitoring chip. The choice of sensors is based on a proprietary industrial application centred around reliability of high-value telecommunications components during shipping and storage, where monitoring and logging of temperature, humidity, corrosion, gas thermal conductivity and gas flow rates are needed. Characterization results, including corrections for cross-sensitivities, are presented for each sensor, all of which are integrated on a single silicon substrate. Preliminary sensor designs and results have been described in [8] although they had been fabricated on independent substrates at that time; this paper extends that work to describe a new fabrication process that integrates all the sensors on a single die to allow further miniaturization by improving the level of integration of the sensors at a lower cost and simplify their deployment and use on environmental WSN platforms. The paper also provides guidelines for the elimination of cross-sensitivity effects.

Final integration of this MEMS-based multisensor chip on a Tyndall25 node used as a data-logging and communications platform is also briefly described at the end of this paper. When compared to the majority of other current modules, this solution offers greater simplicity of operation, lower costs of production and utilization as well as data collection from a greater number of sensors: existing solutions generally consist of fewer sensing capabilities [6] or are comprised of a number of larger discrete sensors [9].

\section{Fabrication Process}

A novel low-temperature process combining surface and bulk micromachining techniques has been developed for the manufacture of integrated MEMS sensors. All the fabrication steps presented in Figure 2 are part of an above-IC process that is CMOS compatible. If needed, a monolithic approach with underlying CMOS may allow the fabrication of on-chip signal conditioning circuits, thus helping miniaturization and system integration even further. 
Figure 2. Schematic of the Microelectromechanical Systems (MEMS)-based multisensor fabrication process.

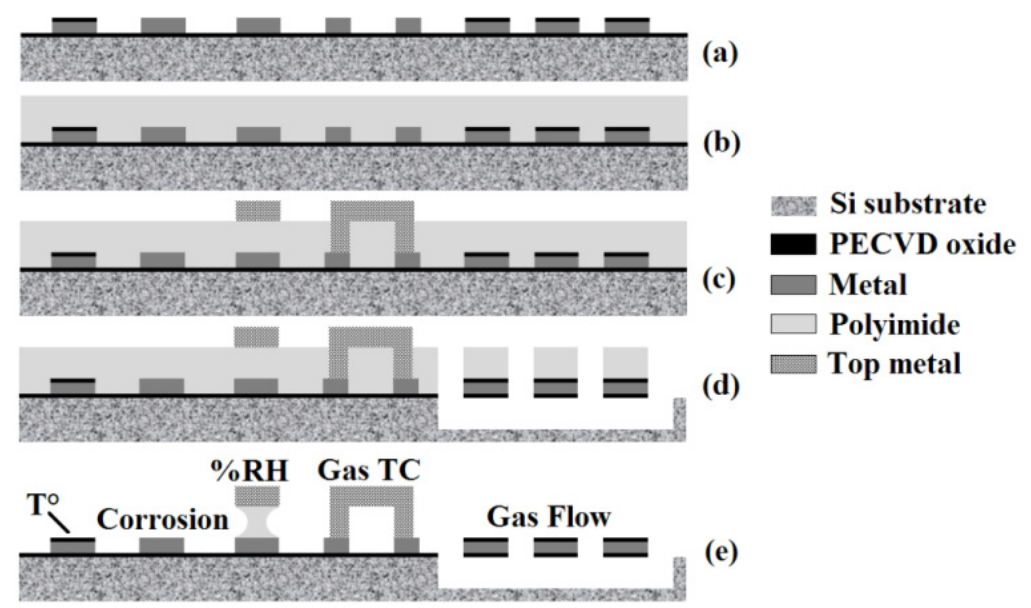

\subsection{Bottom Metal Layer}

A $0.5 \mu \mathrm{m}$ thick layer of Al-1\%Si with a sheet resistance of approximately $65 \mathrm{~m} \Omega / \Upsilon$ is sputtered on a $0.9 \mu \mathrm{m}$ thick layer of Plasma Enhanced Chemical Vapour Deposited (PECVD) silicon oxide and patterned to form the bottom layer of the MEMS structures. It forms temperature sensors, corrosion sensors and the active elements of the gas flow sensor, plus all contact bondpads, bottom electrodes and interconnects. In a CMOS-MEMS monolithic run, the first deposited metal layer may be the final metallization of the CMOS process.

A $125 \mathrm{~nm}$ thick layer of PECVD silicon oxide is then deposited as a passivation layer [Figure 2(a)] to avoid undesired oxidation of the metal and protect underlying CMOS. Contact via holes are opened using a dry etch process where needed: over gas sensor anchors and bondpads to ensure electrical contact between bottom and top electrodes, over the bottom electrode of the humidity sensor, and over the corrosion sensors to remove protective coating against oxidation.

\subsection{Polyimide Layer}

A $3 \mu \mathrm{m}$ thick polyimide layer (DuPont PI 2545) is then spin-coated over the wafer and cured according to the manufacturer's instructions to act as a sacrificial layer for the gas thermal conductivity (TC) sensor and to form the moisture-sensitive active layer of the humidity sensor. A timed dry etch is then used to pattern the polyimide to form anchor openings for the thermal conductivity sensor beam and humidity sensor top electrode.

\subsection{Top Metal Layer}

The final metal level defines the patterned top electrode of the humidity sensor and the structural layer of the suspended gas thermal conductivity sensor, as depicted in [Figure 2(c)]. Prior to metal deposition, the polyimide and exposed metal contacts undergo a $25 \mathrm{~min} 1 \mathrm{~kW}$ RF etch in order to improve adhesion and electrical contacts. In this case, pure aluminium is used as a structural metal, although alternatives such as platinum and titanium may also be used. 


\subsection{Silicon Underetching}

A multilayer anisotropic etch through the polyimide/oxide/metal/oxide stack is then carried out. This patterned stack then acts as a hard mask for a subsequent isotropic etch of the bulk silicon [10], as presented in Figure 3. The vertical etch depth is approximately $160 \mu \mathrm{m}$.

Figure 3. Transverse cross-section and Scanning Electron Microscope (SEM) detail of $160 \mu \mathrm{m}$ silicon underetch.

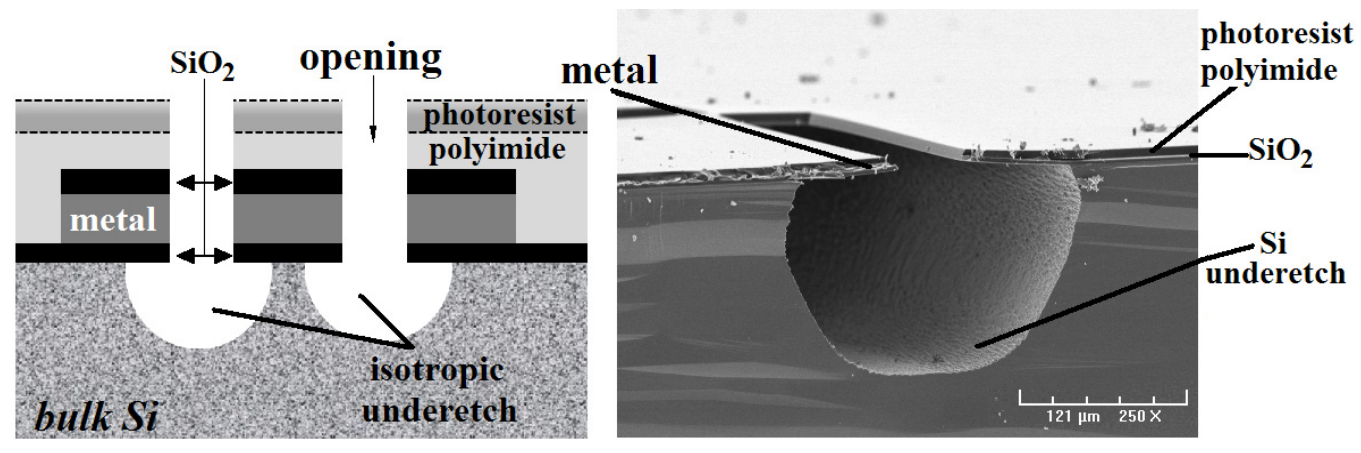

\subsection{Polyimide Removal}

The wafer is first diced before MEMS multisensor fabrication is finally completed by using a timed etch to selectively remove sacrificial polyimide. During wafer dicing, the polyimide layer also protects the suspended structures against possible damage. Figure 4 shows images of fabricated MEMS multisensor dies.

Figure 4. SEM and microscopic images of two examples of MEMS multisensor dies with different layouts.

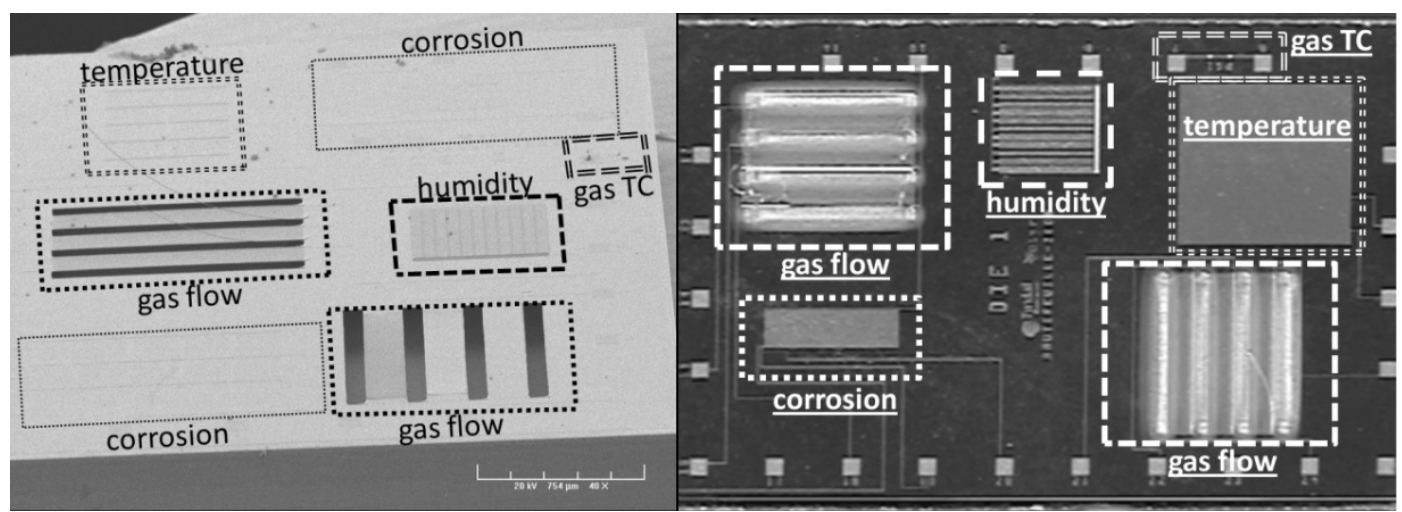

\section{Sensors Characterization and Test}

For the environmental humidity and temperature tests described in the following sections, the dies have been tested in a TAS HTCL225 climatic chamber [11]. Humidity and temperature inside the chamber are measured using calibrated commercial sensors. MEMS sensor resistance values have been measured using Keithley 2430 and Agilent 34411A multimeters, and capacitance measurements were read on an Agilent 4284A LCR meter with an AC bias of $50 \mathrm{mVrms}$ at a frequency of $100 \mathrm{kHz}$. The substrates of the die were grounded to avoid parasitic charges, while the output data was both saved 
and displayed using an Agilent VEE software program. The thermal conductivity sensor has been tested in a vacuum chamber where different gases have been introduced after an initial purge, and measurements have been taken using a Keithley 4200A semiconductor parameter analyzer. Finally, a custom-built gas flow chamber has been constructed to precisely control air flow velocity over the surface of the bare die.

\subsection{Humidity Sensor}

Capacitive relative humidity $(\mathrm{RH})$ sensors consist of a moisture-sensitive dielectric material sandwiched between two metallic electrodes [11]. In order to allow moisture to ingress into the dielectric layer, the sensor is split into 23 "fingers", each having a $40 \mu \mathrm{m}$ wide and $1,150 \mu \mathrm{m}$ long top electrode, Figure 5. Underneath each finger is a $20 \mu \mathrm{m}$ wide bottom electrode which defines the common surface area of the capacitor. The sacrificial polyimide is selectively removed from field areas and from underneath the thermal conductivity sensor, but not from the active area of the humidity sensor, by undercutting the top electrode using isotropic etching in oxygen plasma, [Figure 2(e)]. The total area of the sensor is $1.2 \mathrm{~mm} \times 1.2 \mathrm{~mm}$, and the capacitance of the sensor has been simulated using the finite element modelling program Coventorware as $7.6 \mathrm{pF}$ at $50 \% \mathrm{RH}$.

Figure 5. Detail of relative humidity sensor. Each top-electrode finger measures $1,150 \mu \mathrm{m} \times 40 \mu \mathrm{m}$ and covers a $3 \mu \mathrm{m}$ thick polyimide active layer deposited on top of the fingered bottom electrode.

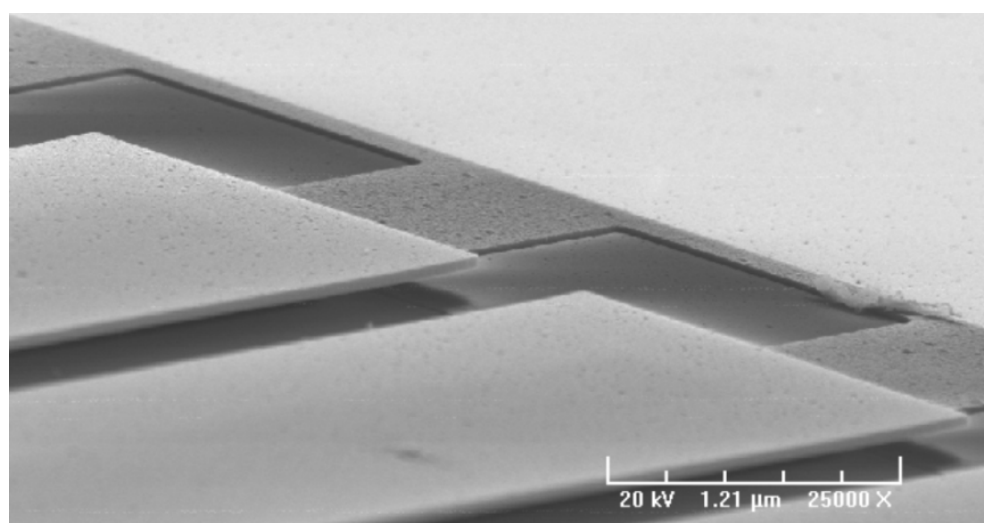

The dielectric constant of the polyimide layer determines the sensitivity of the structures to humidity variations and is easily measured using electrical capacitance measurements [8]. Generally, the relative dielectric constant $\varepsilon_{r}$ of polyimide is considered to vary in the same manner over similar relative humidity ranges because the water molecules are assumed to diffuse through the entire polyimide layer following a bulk phenomenon. According to [12], the variation of capacitance as a function of water ingress is:

$$
\frac{C_{\text {wet }}}{C_{d r y}}=\frac{\varepsilon_{\text {wet }}}{\varepsilon_{d r y}}=\frac{\left(\gamma\left(\varepsilon_{\text {water }}^{1 / 3}-\varepsilon_{d r y}^{1 / 3}\right)+\varepsilon_{d r y}^{1 / 3}\right)^{3}}{\varepsilon_{d r y}}
$$

where $\gamma$ is the polyimide-dependent fractional volume of water at a certain relative humidity level (expressed in \%), $\varepsilon_{\text {water }}$ is the dielectric constant of water $(=78)$, and $\varepsilon_{d r y}$ is the dielectric constant of 
polyimide in the dry state. The sensitivity of a humidity sensor expressed as a ratio of capacitive fluctuations $\Delta C$ to relative humidity variations $\Delta R H$ would then be given by:

$$
S=\frac{\Delta C}{\Delta R H}=\frac{\left(\frac{\varepsilon_{\text {wet }}}{\varepsilon_{d r y}}-1\right) \times C_{d r y}}{\Delta R H}
$$

The information available in the datasheet of the polyimide layer used in this structure (PI2545 from HD Microsystems) gives $\varepsilon_{r}=3.5$ at $50 \% \mathrm{RH}, \gamma=1.2 \%$ at $35 \% \mathrm{RH}$ and $\gamma=3.1 \%$ at $85 \% \mathrm{RH}$ [13]. This suggests that sensor sensitivity varies over the full humidity range, and that three linear phases may be expected. A modified analytical model of the variation in dielectric constant as a function of relative humidity was then calculated. The fractional volume of water given in the datasheet was used to determine $\varepsilon_{r}$ in three different phases $(0 \%<\mathrm{RH}<35 \%, 35 \%<\mathrm{RH}<50 \%, 50 \%<\mathrm{RH}<100 \%)$, and it was assumed that the dielectric constant is constant within these three phases. Finally, a relative permittivity of $\varepsilon_{r}=5$ at $50 \% \mathrm{RH}$ has been experimentally determined, although a constant $3 \mu \mathrm{m}$ thickness has been measured for the polyimide layer thickness. This larger-than-expected value may be explained by the use of plasma etch techniques that modified the capacity of penetration and adhesion of moisture inside the polymer material during fabrication [14]. The resulting 3-phase analytical model describing the performance of the sensors for a $3 \mu \mathrm{m}$ thick polyimide layer sandwiched between metal plates closely matches experimental data (Figure 6).

Figure 6. 3-phase analytical model and experimental performance of the humidity sensor (average data and dispersion for 5 humidity cycles).

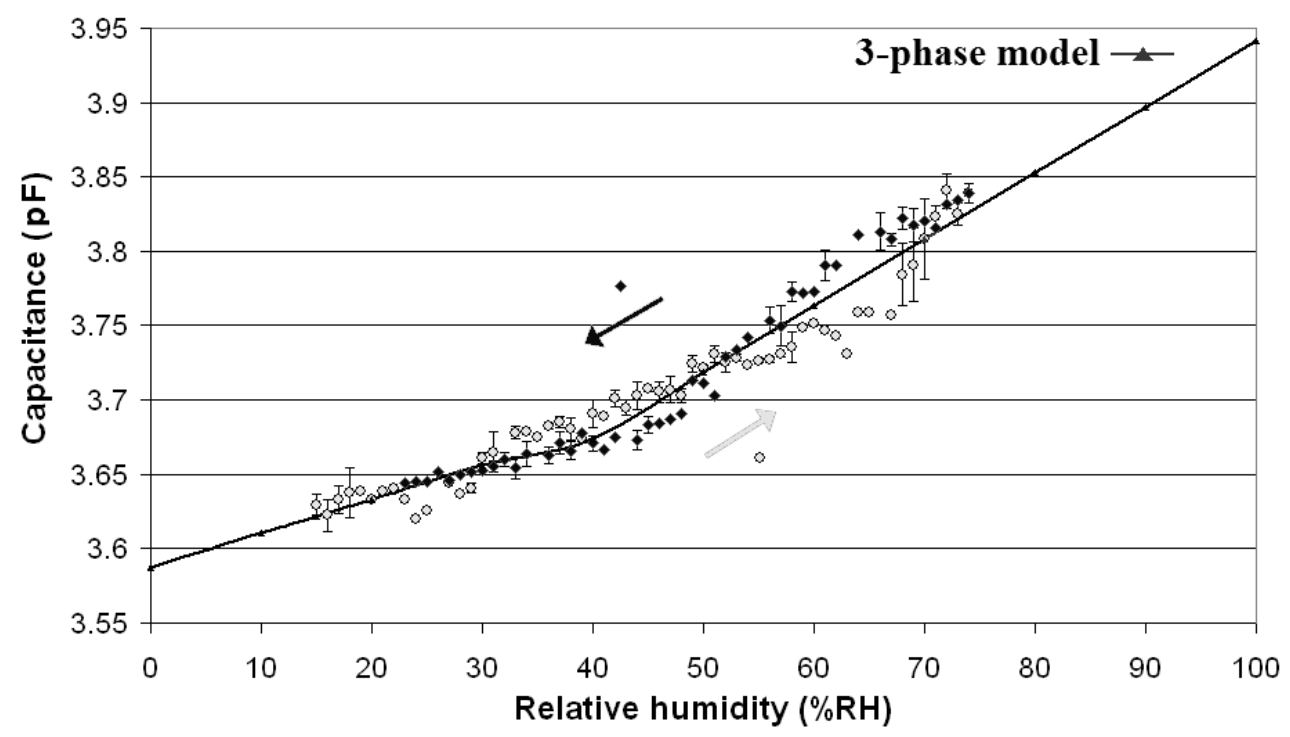

A maximum hysteresis of $10 \% \mathrm{RH}$ can be measured when humidity is ramped up and down. No hysteresis was measured for humidity levels varying at a rate lower than $1 \% \mathrm{RH}$ per minute. Although this should not affect future readings during normal deployment in the target application where humidity varies slowly, dynamic absorption and desorption rates have been carefully analyzed. Assuming that the sensor exhibits Fickian diffusion [15], and that the humidity at each side of the finger is constant and identical, the time-varying electrical capacitance of the sensor $\left(C_{t}\right)$ when subjected to a sudden change in ambient humidity is given by: 


$$
\frac{C_{t}}{C_{\infty}}=1-\sum_{n=0}^{\infty} \frac{8}{(2 n+1)^{2} \pi^{2}} \exp \left(\frac{-D(2 n+1)^{2} \pi^{2} t}{4 l^{2}}\right)
$$

where $2 l$ is the lateral width of the film and $D$ is the polyimide diffusion coefficient [16]. The experimentally measured diffusion coefficient of $0.9 \times 10^{-12} \mathrm{~m}^{2} / \mathrm{s}$ is slightly lower than the datasheet value of $2.5 \times 10^{-12} \mathrm{~m}^{2} / \mathrm{s}$, Figure 7 . This variation has already been reported for moisture desorption in polyimides that suffered the use of $\mathrm{SF}_{6}$ during $\mathrm{O}_{2}$ plasma etching [17], as is the case for our dielectric layer during the silicon underetching step [10].

Figure 7. Dynamic behaviour of the humidity sensor: desorption and absorption rates.
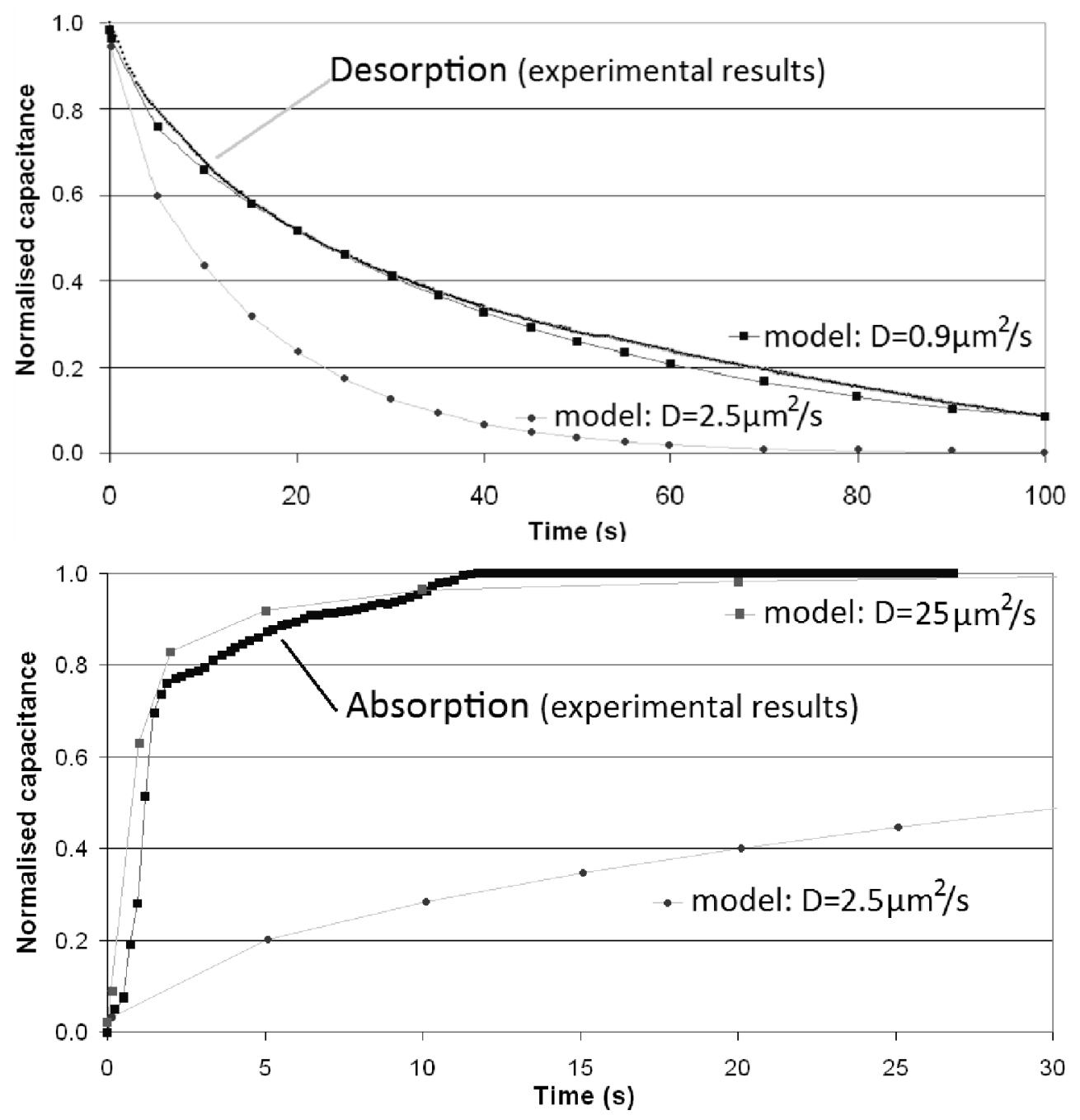

The measured diffusion coefficient is significantly greater than the measured absorption coefficient. This type of discrepancy has also been observed in other polyimide-based humidity sensors and has previously been explained by the modification of polyimide morphology by plasma treatment [18].

Finally, physical ageing of the sensor has also been investigated, as its hygroscopic nature may degrade with long-term exposure to humidity and variations in temperature [19]. Figure 8 shows a comparison between a virgin sensor [Figure 8(a)] and one structure aged at $85 \% \mathrm{RH}$ and $50{ }^{\circ} \mathrm{C}$ for 16 days [Figure $8(\mathrm{~b})$ ]. Both the dielectric constant and the dissipation factor are presented as a function of measurement frequency. 
Figure 8. (a) Dielectric characteristics of a virgin humidity sensor; (b) Evidence of physical ageing of the humidity sensor.
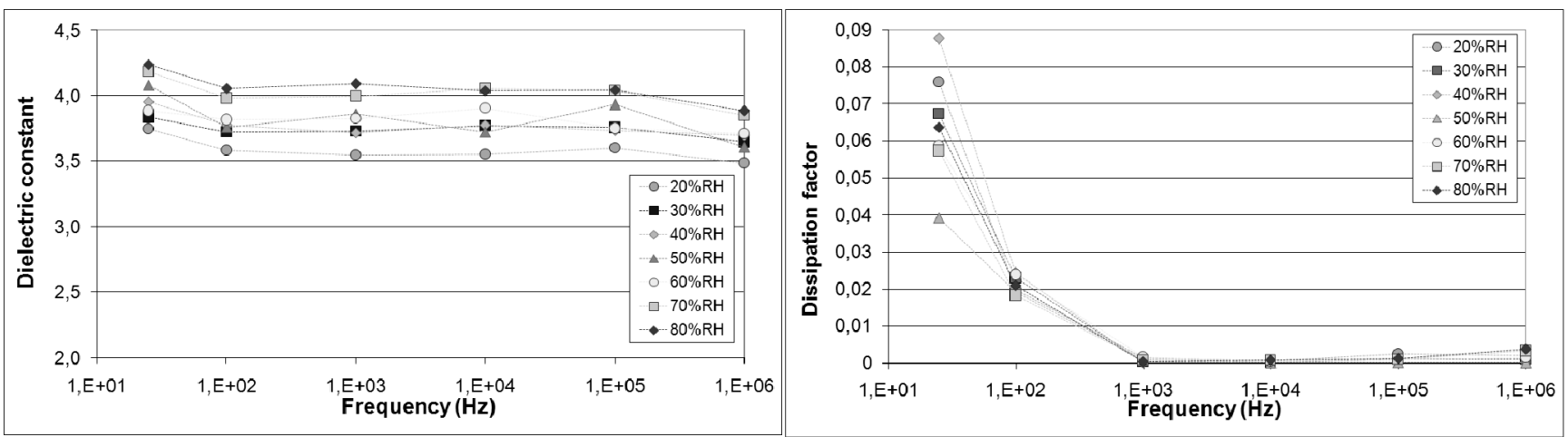

(a)

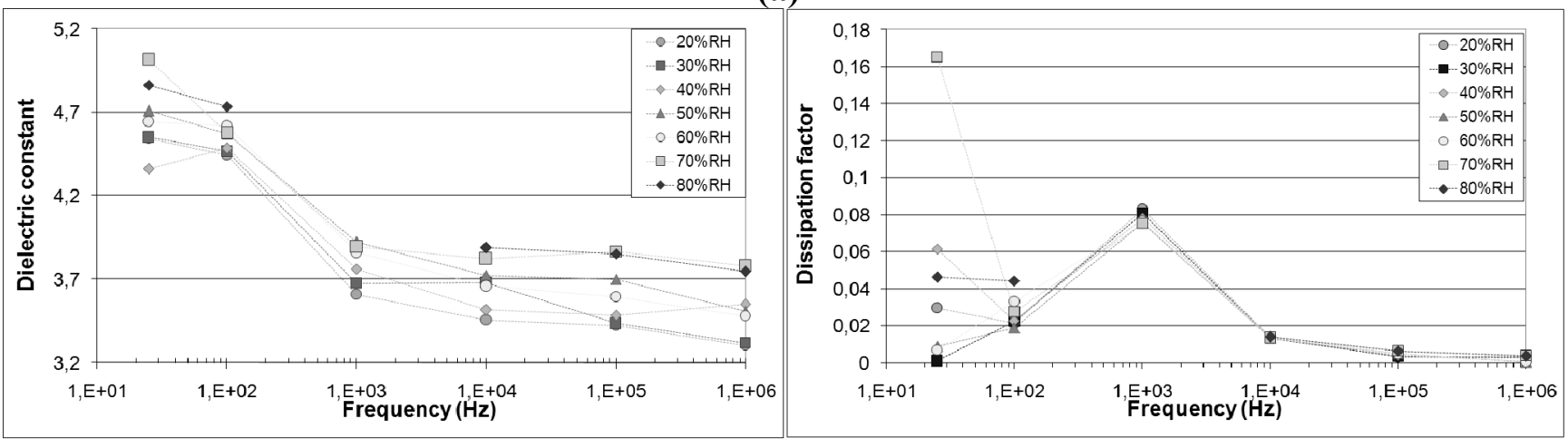

(b)

The uncertainties observed at low frequency are common in parallel-plate capacitance measurements and are caused by limited precision of the instrument [20]. However, the aged die shows a frequency relaxation at $1 \mathrm{kHz}$ that may be caused by the presence of conductive ions that penetrated polyimide with moisture, and cause frequency-dependent dipole relaxation [20]. When characterized several months later, the aged structure did not appear to show any further deterioration. This ageing phenomenon is important to consider before integration on a multisensor module and the relaxation frequency will have to be avoided during sensor interrogation.

\subsection{Temperature Sensor}

The two temperature structures $\left(\mathrm{TS}_{\mathrm{a}}\right.$ and $\mathrm{TS}_{\mathrm{b}}$ ) integrated on the multisensor cell were fabricated from a $2 \mu \mathrm{m}$ wide, $0.5 \mu \mathrm{m}$ thick $\mathrm{Al} / 1 \% \mathrm{Si}$ line, drawn in a meander configuration to save space and passivated with a $125 \mathrm{~nm}$ oxide layer in order to avoid corrosion. The principles and preliminary performances of these temperature sensors have been detailed in [8].

Figure 9 shows the performance of two sensors that differ only by their total length $L$, $\left(L\left(T S_{a}\right)=143 \mathrm{~mm}\right.$ and $\left.L\left(T S_{b}\right)=250 \mathrm{~mm}\right)$. Respective sensitivities of $20.84 \Omega /{ }^{\circ} \mathrm{C}$ and $37.12 \Omega /{ }^{\circ} \mathrm{C}$ are observed. A worst case of $0.3 \%$ hysteresis has been measured which is within the required precision of the sensor and does not require correction. 
Figure 9. Temperature sensors performance.

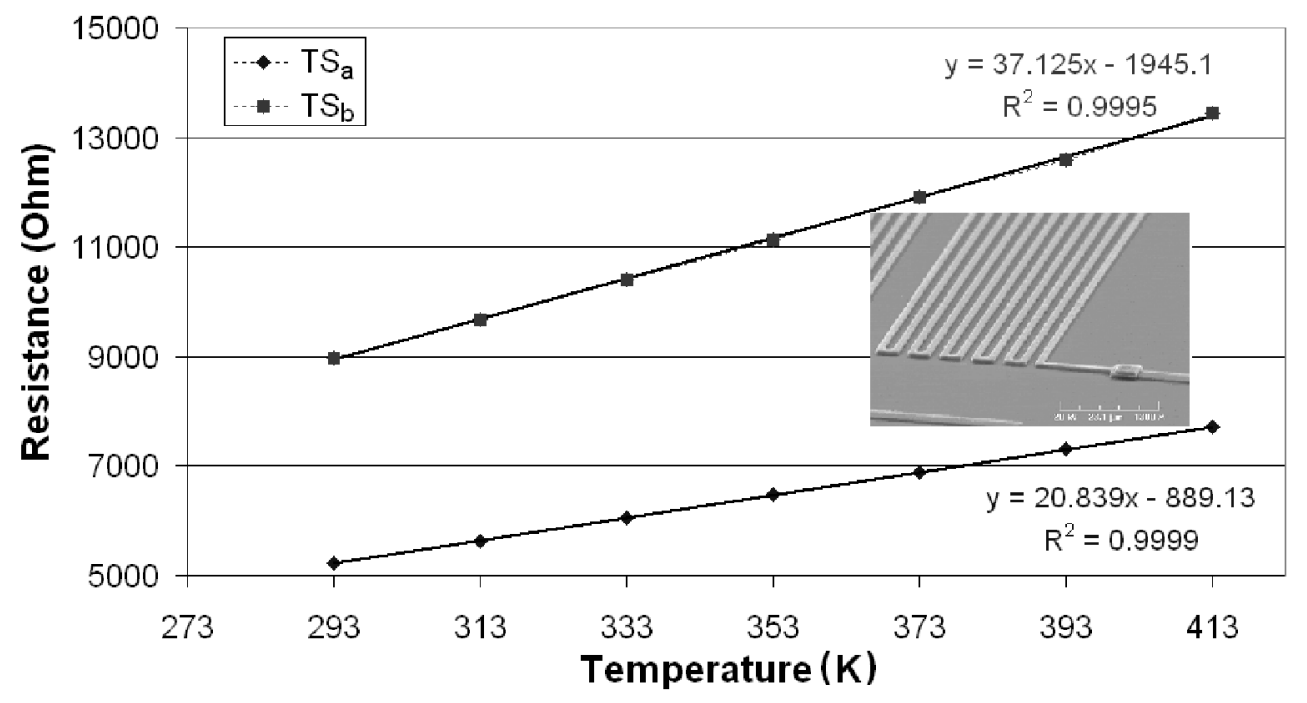

No discrepancies due to ageing have been observed for this sensor.

\subsection{Thermal Conductivity Sensor}

Thermal conductivity sensors operate by measuring variations in the thermal conductance of a structure in response to changes in the surrounding ambient, and may be configured for use in a range of sensing applications, such as infra-red cameras, flow velocity sensors, Pirani gauges and gas detection systems. This section demonstrates one such structure and illustrates its sensitivity to gas and pressure variations. The sensor consists of $100 \mu \mathrm{m}$ to $150 \mu \mathrm{m}$ long suspended aluminium beams of cross-sectional area $1 \mu \mathrm{m} \times 5 \mu \mathrm{m}$. Operating principles and preliminary performances were presented in [8]. Although the structures remained relatively flat above the substrate after release, a current-dependent bending of the structures due to Joule heating was observed, Figure 10. As the sensitivity of the structure depends on the beam-to-substrate gap, this effect causes a large reduction in sensitivity and eventually leads to thermomechanical failure of the beam. Low power is therefore an essential requirement for sensor operation.

Figure10. Optically measured bending profile of a $150 \mu \mathrm{m}$ long gas sensor structure.

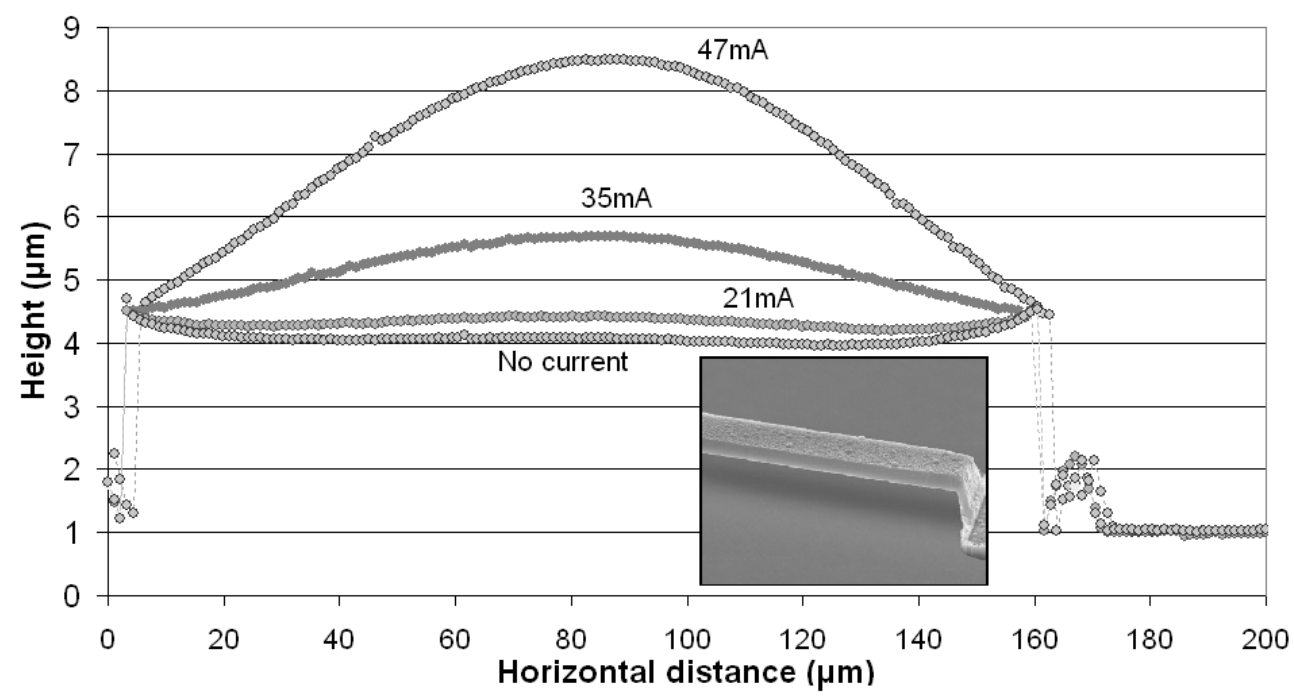


For $100 \mu \mathrm{m}$ long structures, measured values of thermal conductance were approximately 15 times larger than expected. This was due to the effects of mechanical stress that left the beams with a bowed-down shape. This thinner substrate-to-structure airgap had a minimum of approximately $0.1 \mu \mathrm{m}$ and enhanced the subsequent sensitivity of the sensors. The behaviour of $100 \mu \mathrm{m}$ long sensors has been examined in different gas environments with argon, helium and air. The evolution of thermal conductance $G$ as a function of pressure is presented in Figure 11 and clearly demonstrates that the sensor is capable of measuring pressure in the $1-1,000$ mbar range. The capability of the sensor to detect argon at atmospheric pressure has already been demonstrated in [8]. Helium has a thermal conductivity 5.84 times greater than that of air, making it a good other candidate for detection by our sensor [21]. However, a lower $\Delta G_{H e} / \Delta G_{\text {air }}$ ratio of 4.54:1 is measured at atmospheric pressure. This reduction of approximately $22 \%$ may be explained by a lower thermal conductivity of helium than expected, as it is very much dependent on the ambient conditions [22]. Clearly, the device measures thermal conductance rather than absolute pressure or gas mixture, so this will limit application areas to those where variations in both gas composition and pressure cannot occur simultaneously, or where a change in ambient thermal conductivity may be indicative of a more significant issue.

Figure 11. Illustration of the gas-sensitive nature of the thermal conductance of the structure.

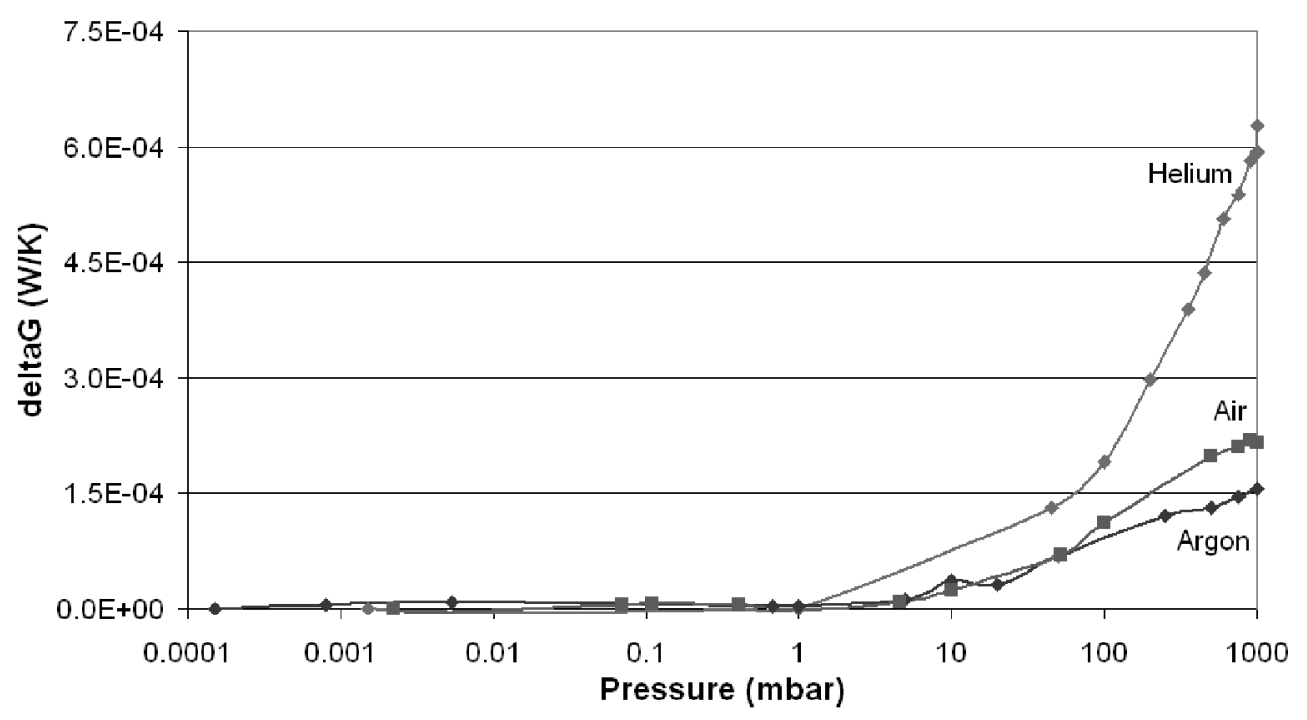

To simplify the determination of the thermal conductance $G$ when the multisensor chip is integrated on a wireless module, it is possible to derive it from an electrical resistance $(R)$ measurement when a constant voltage $V$ is applied across the structure [23]. In this case, it is important to limit the input voltage to $0.5 \mathrm{~V}$ to avoid high currents and physical damage to the structure.

\subsection{Gas Flow Velocity Sensor}

The gas flow velocity sensor consists of three similar metallic meander structures: one resistive heater in the centre with two temperature sensors located upstream and downstream [24]. They are $15.15 \mathrm{~mm}$ long, $5 \mu \mathrm{m}$ wide and $0.5 \mu \mathrm{m}$ thick. As a result of the selective silicon underetching, they are suspended on $1 \mu \mathrm{m}$ thick silicon dioxide beams and are separated from each other by $80 \mu \mathrm{m}$ openings (Figure 3). This isolation of the structure results in excellent thermal performance [24]. According to [25], in the presence of an air flow at its surface and under a constant electrical input power $P_{i n}$, the 
temperature of the heater decreases and the flow-rate $v$ is detectable by measuring this temperature change $\Delta T_{0}$ :

$$
\Delta T_{0}=\frac{P_{\text {in }}}{A+B \sqrt{v}}
$$

where $A$ and $B$ are dimensionless calibration constants dependent on the geometry of the structure, the sensor materials and the flow. Figure 12 shows the experimental evolution of the heater temperature as a function of the air flow at its surface for $P_{i n}=30 \mathrm{~mW}\left(T=86^{\circ} \mathrm{C}\right)$. Temperature variations $\Delta T$ have been experimentally determined for different flow-rates of air from the measured electrical currents $I_{\text {in }}$ flowing through the heater under constant input voltage $V_{i n}$, the thermal coefficient of resistance (TCR) $\alpha$ of the structure material and the resistance $R_{0}$ of the structure when $V_{i n}=I_{\text {in }}=0$ :

$$
\Delta T=\frac{V_{\text {in }}-R_{0} I_{\text {in }}}{\alpha R_{0} I_{\text {in }}}
$$

A relatively good correlation with the analytical model can be observed with $A=-4.41 \times 10^{-3}$ and $B=4.77 \times 10^{-3}$ and a measured TCR of $0.00395 \mathrm{~K}^{-1}$.

Figure 12. Air flow detection by temperature variation at heater location $\left(\mathrm{P}_{\text {in }}=30 \mathrm{~mW}\right)$.

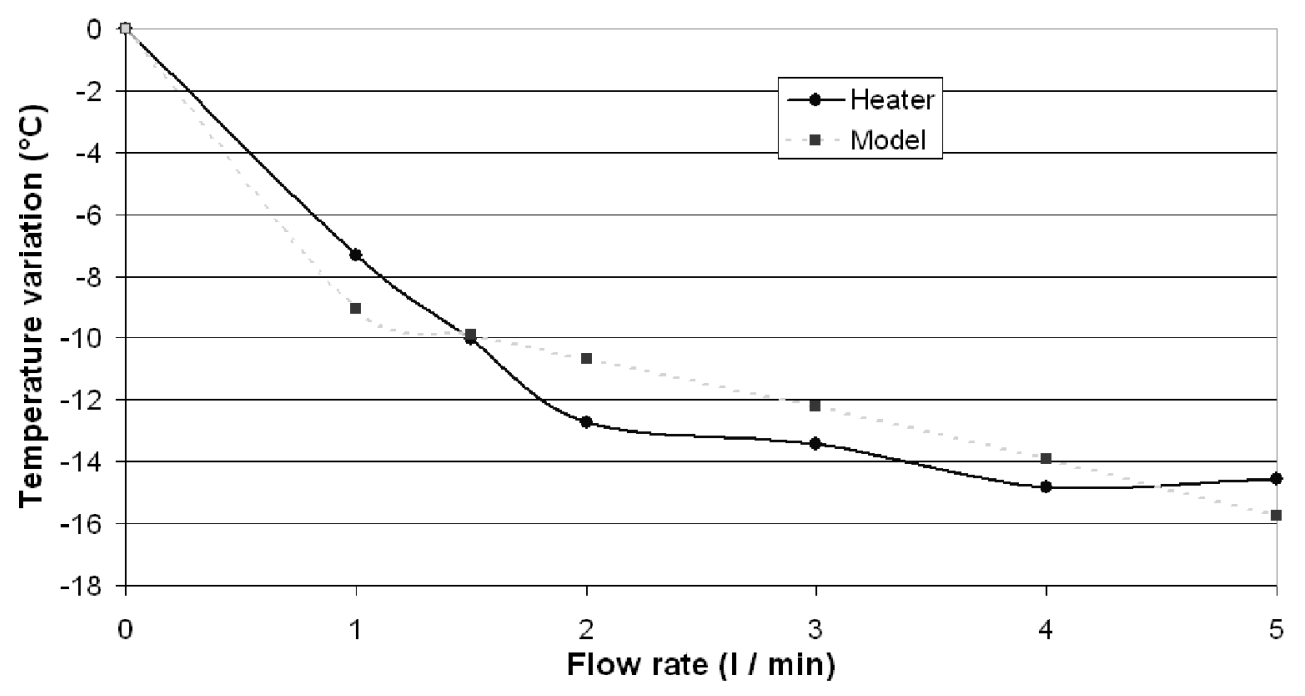

In the presence of an air flow, the three-structure sensor allows the determination of flow velocity by heating the middle structure and measuring the temperature difference between the two temperature sensors located downstream $\left(T_{\text {down }}\right)$ and upstream $\left(T_{u p}\right)$. Due to the differential nature of the structure, the temperature evolution measured upwards and downwards is no longer proportional to $v^{1 / 2}$, but two equations defining the temperature profile on each side of the heater have been given in a complete analytical model [25]. Figure 13 gives the calculated temperature difference $T_{\text {down }}-T_{u p}$ as a function of the flow velocity for varying power input.

Results show that this sensor configuration is capable of flow velocity measurements even with low electrical input power. However, the overall sensitivity is not as high as expected and the sensor displays greatest sensitivity in the 2-3 litres per minute range. Extensive comparison between different models seems to indicate that this limitation can be optimized in future prototypes by the incorporation of a ducting channel in the design. 
Figure 13. Determination of the flow direction and velocity with a three-structure sensor.

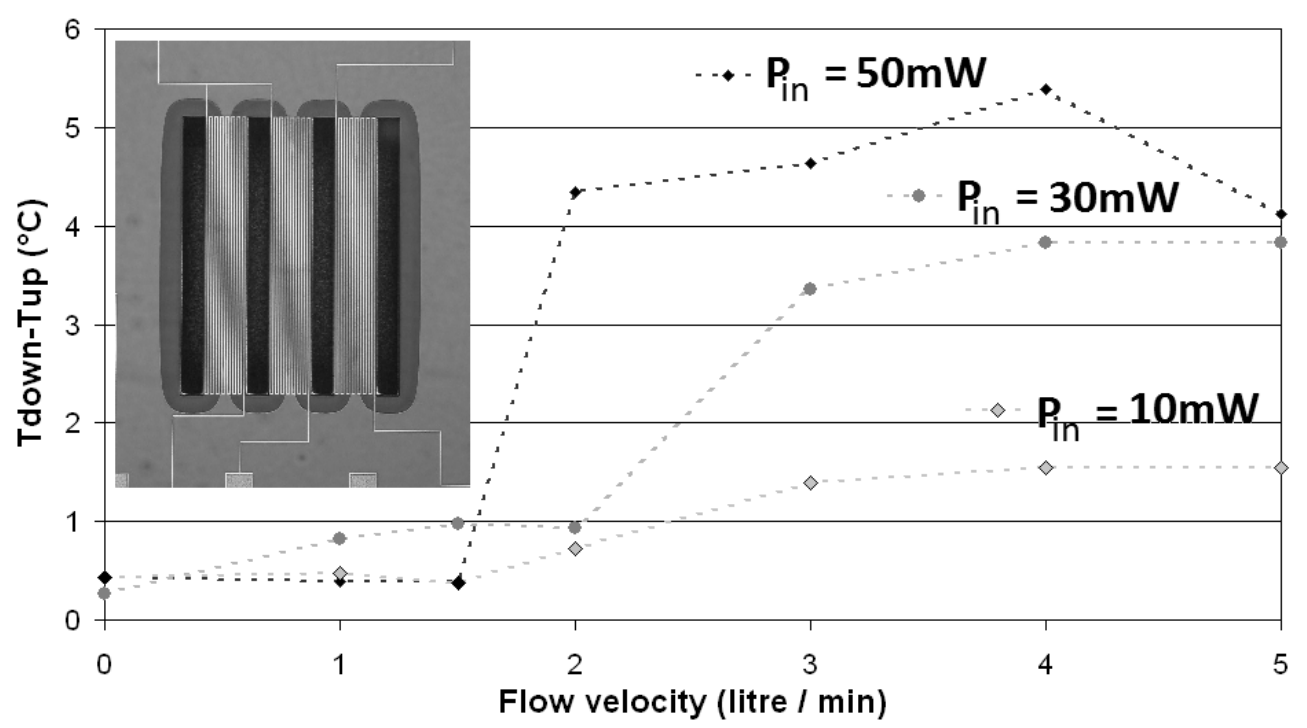

\subsection{Corrosion Sensor}

Because of selective removal of the passivation layer covering the bottom metal layer, it has been possible to fabricate early-warning corrosion sensors. Inversely biased leakage current detectors have been implemented to monitor the evolution of electrolytic migration between tracks in the presence of moisture, salts and other impurities that influence aluminium degradation [26]. The structures consist of interdigitated triple track comb patterns which suffer greater total leakage currents between their electrodes than single rungs (measured respectively in the $\mu \mathrm{A}$ and $\mathrm{nA}$ ranges) and enable direct resistance readings even under low voltage bias [24]. A $2 \mu \mathrm{m}$ electrode spacing has been selected to optimise the corrosion rate between tracks; the tracks themselves are $2 \mu \mathrm{m}$ wide. Figure 14 displays a typical response of an $800 \mu \mathrm{m}$ long triple-track serpentine structure suffering a humidity ramp at $60{ }^{\circ} \mathrm{C}$ under a $3.3 \mathrm{~V}$ bias.

Figure 14. Corrosion rate of an $800 \mu \mathrm{m}$ long triple track structure (3.3V bias). Inset: The same structure fully corroded after several days (optical microscope image).

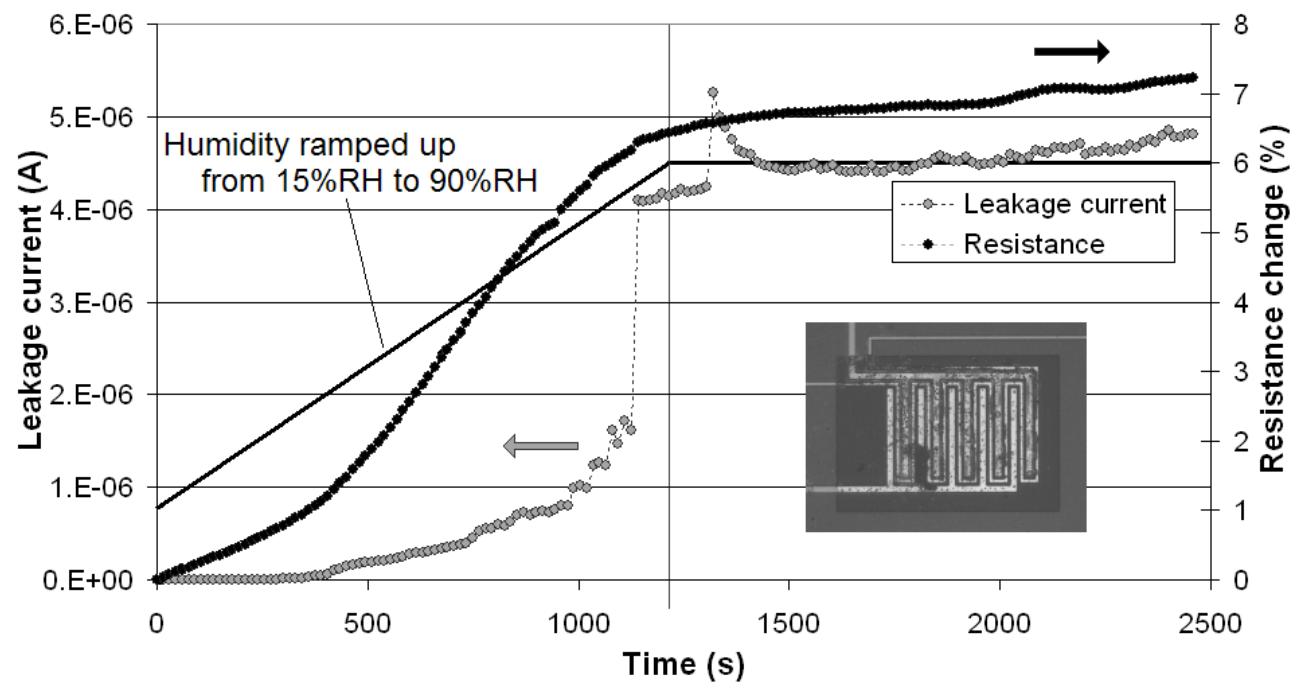




\section{Cross-Sensitivity}

When data are captured simultaneously from different sensors, strongly interdependent variables and cross-sensitivities can modify the sensor outputs. In order to ensure reliable sensor interpretation, we are proposing a few compensation techniques similar to that already presented in [24] for preliminary prototypes. This paper extends those techniques to cover the wider range of sensors presented here.

\subsection{Correction of Undesirable Temperature Influences}

Due to the temperature dependency of the electrical resistance of all metals, temperature changes will affect all onboard resistive sensors. Nevertheless, this can be easily compensated by using the temperature sensor as an absolute reference, and thus eliminating temperature-induced contributions from other resistive readings. On intelligent WSN modules, this can be achieved in real-time by user-defined signal processing or later, during data analysis.

Although the diffusion coefficient of polyimide materials is a function of temperature [27], some affirm that temperature has no influence on the hysteresis response of polyimide humidity sensors [28]. In previous work, we offered a simple technique to isolate temperature contributions in our parallel plate humidity sensor readings [24].

For the humidity sensor, the equation of temperature-dependent average sensitivity $S$ (in fF per $\% \mathrm{RH}$ ) has been calculated and expressed as a function of the measured temperature $T$ by the following expression:

$$
S(T)=6.81 \times 10^{-6} \times T^{4}-12.44 \times 10^{-4} \times T^{3}+7.089 \times 10^{-2} \times T^{2}-1.221 \times T+13.891
$$

To simplify, it was decided to compensate the temperature influence on sensor sensitivity regardless of hysteresis. Experiment shows that this is a very acceptable approximation.

\subsection{Correction of Undesirable Humidity Influence}

In principle, ambient humidity may only affect non-passivated metal structures and in an irreversible manner. In this work, a significant influence of humidity on temperature sensor performance has been observed at low or medium humidity levels [24]. The correction procedure derived for temperature sensors may be extended to all resistive sensors on the same substrate.

More interestingly, it seems that condensed moisture affects the electrical resistance of $\mathrm{Al}-1 \% \mathrm{Si}$ tracks deposited on the substrate, even when passivated and regardless of their geometrical structure. The evolution of the electrical resistance of metal tracks of different lengths, widths and shapes has therefore been studied in a humid environment. It has been observed that $\mathrm{SiO}_{2}$ thickness plays an important role in moisture dependency. Figure 15 shows the humidity dependence of resistive sensors for various underlying oxide thicknesses. During this experiment, temperature was kept constant at $80{ }^{\circ} \mathrm{C}$ to obtain condensed moisture in the chamber and humidity was ramped up and down from $10 \% \mathrm{RH}$ to $80 \% \mathrm{RH}$ at a rate lower than $1 \% \mathrm{RH}$ per minute. 
Figure 15. Influence of condensed moisture on the resistance of metal lines for different underlying oxide thicknesses.

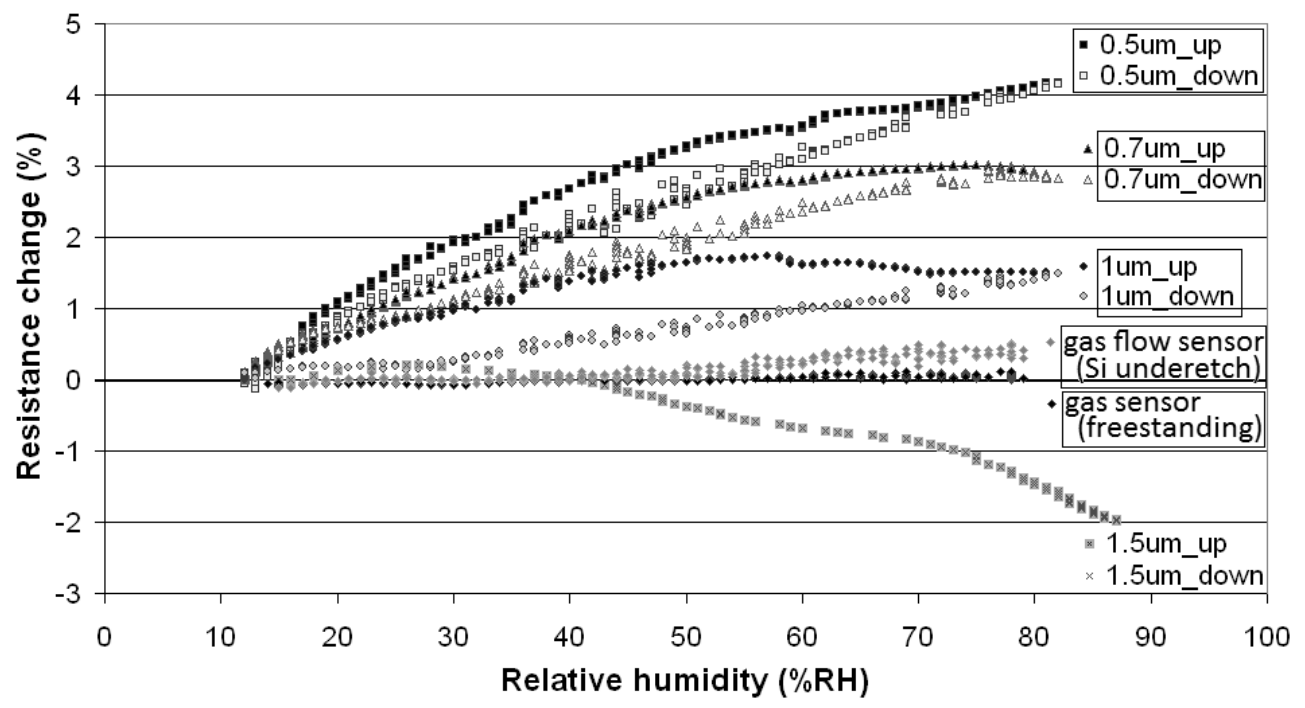

The electrical resistance of all resistive metal structures sitting on top of a thin $\mathrm{SiO}_{2}$ oxide varies reversibly with humidity and a maximal resistance change of $4 \%$ is measured for thinner oxides (this, for example, may be misinterpreted as $\Delta \mathrm{T}=9^{\circ} \mathrm{C}$ ).

Leakage currents have been measured between the bottom metal layer and the Si substrate in the presence of condensed moisture: in the case of a $1 \mu \mathrm{m}$ thick $\mathrm{SiO}_{2}$ layer leakage currents reached approximately $30 \mathrm{nA}$. However, for oxide layers thicker than $1.5 \mu \mathrm{m}$, the effect is inversed as moisture cools the metal [28]. Finally, moisture affects thermally isolated gas and gas flow sensors in a very limited manner. In this case, the phenomenon may be explained by water sorption modifying thermal exchange between the metal structure and ambient air at higher humidity content, especially in the presence of condensation [29].

The explanation of the present effect may be that reversible water adsorption inside such a dielectric swells the $\mathrm{SiO}_{2}[30,31]$. It has also been demonstrated that increasing the thickness of PECVD oxide layers similar to those used in our fabrication process enhances the resistance against moisture ingress [32]. However, even though the oxide layer is relatively conductive when it adsorbs moisture, this does not justify the resistance increase, as the formation of a parallel resistance in the dielectric would decrease the measured value. A possible explanation is that negative charges or ions penetrate the relatively large areas of the silicon substrate in contact with moisture and are physically absorbed inside the metal lines through the underlying oxide when permeable. These may impede the mobility of conductive charges inside the metal, thus increasing the overall resistance. It has been observed that the application of a constant $20 \mathrm{~V}$ positive bias between the silicon substrate and the metal line through a $1 \mu \mathrm{m}$ thick oxide layer cancels the influence of condensed moisture on electrical resistance, probably by attracting negative charges away from the metal line (Figure 16). The resistance change has been calculated with reference to the resistance value in dry air $R_{0}$. 
Figure 16. Reduction of the impact of condensed moisture with time, after the application of a $20 \mathrm{~V}$ bias between silicon substrate and metal line.

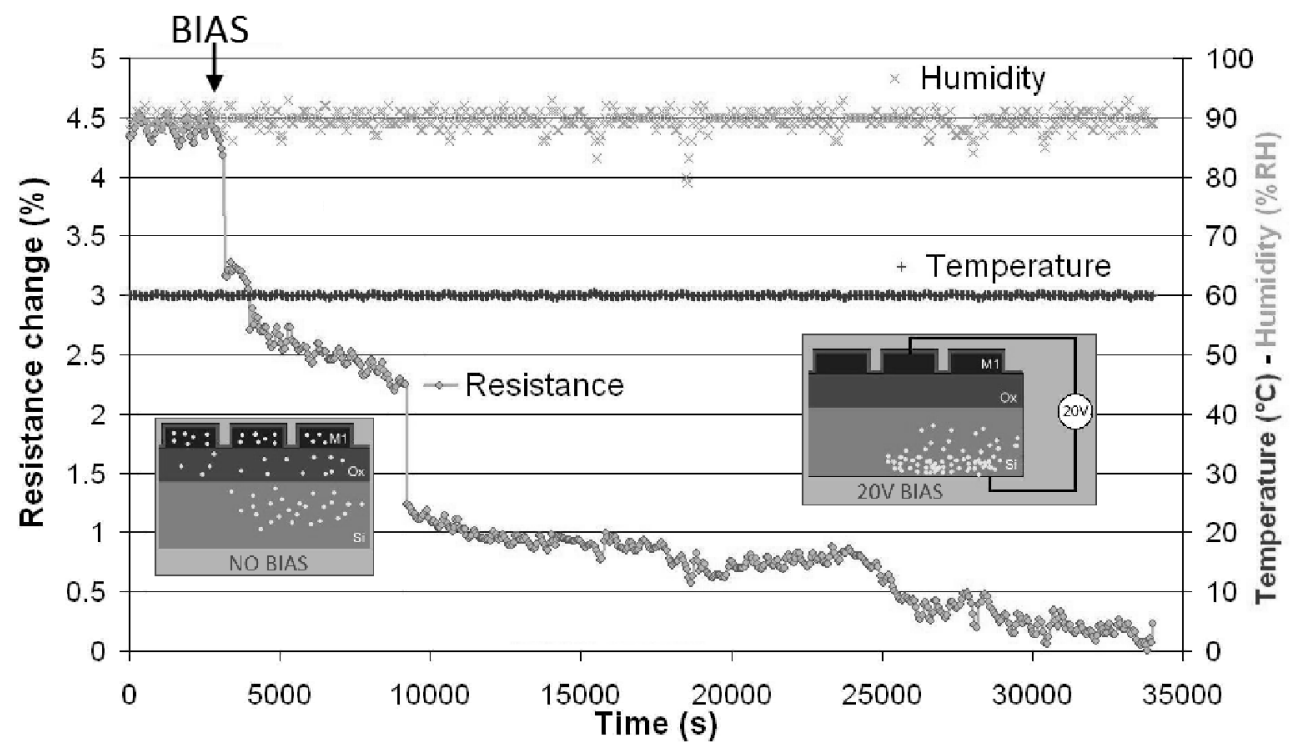

In our final design, passive resistors fabricated on the final MEMS multisensor die are deposited on a $0.9 \mu \mathrm{m}$-thick oxide, so that their resistance increase due to moisture is limited to values less than $2 \%$ greater than what is expected when monitoring to temperature changes only.

\subsection{Correction of Undesirable Pressure Influence}

Experimental results presented in Figure 17 show that pressure changes up to 1 bar have a negligible influence on all resistive sensors except for the thermal conductivity sensor as expected. The humidity sensor output variation of approximately $3.4 \%$ is due to removal of moisture-laden air from the pressure chamber and is reversible.

Figure 17. Influence of pressure on multisensor die.

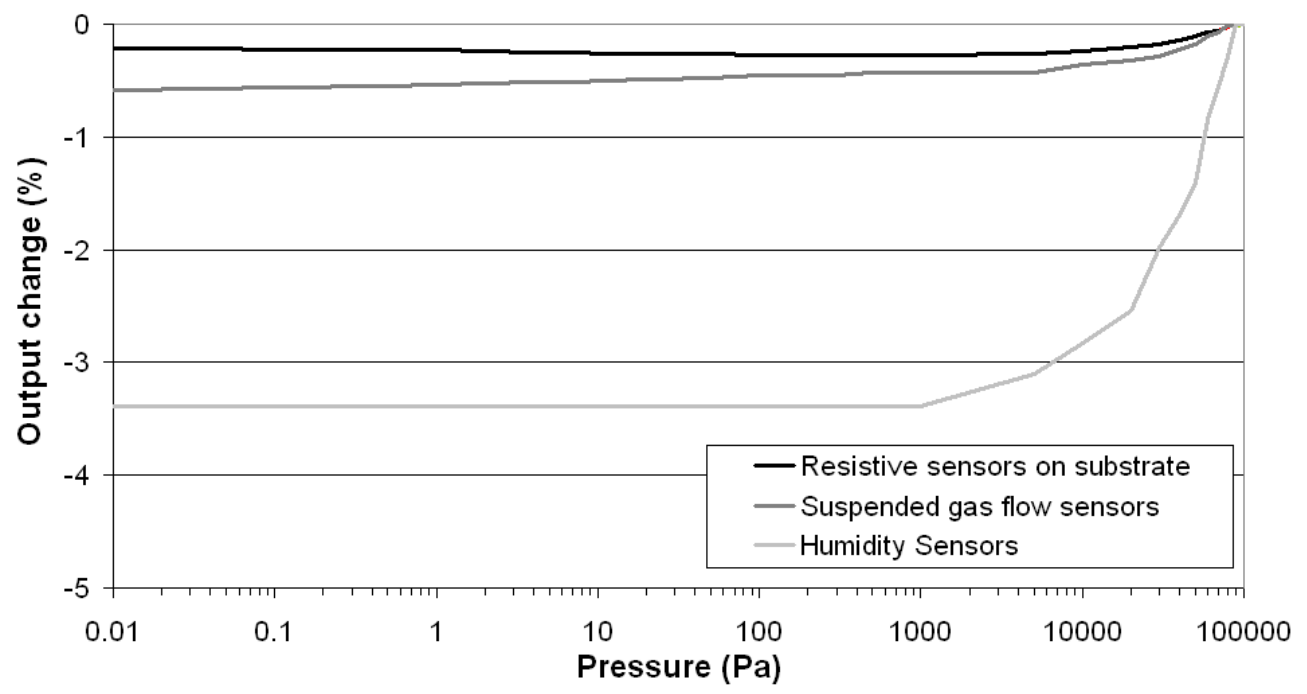

The influence of ambient pressure can therefore be disregarded in cross-sensitivity compensation. 


\subsection{Correction of Undesirable Gas Flow Influence}

Because the final aim of this project is to integrate the multisensor die into a larger system that may be located in open air, the influence of the presence of a gas flow needs to be investigated and compensated. A custom-built gas flow chamber was used to characterise all sensors located on the die in the presence of a gas flow (air) on the surface. It appears that the influence of gas flow on sensor readings can be neglected (Figure 18). In order to avoid any measurement discrepancy caused by the difference between the composition of the ambient and blown air, the chamber has been initially filled with dry air only.

Figure 18. Influence of dry air flow on the surface of the MEMS multisensor die.

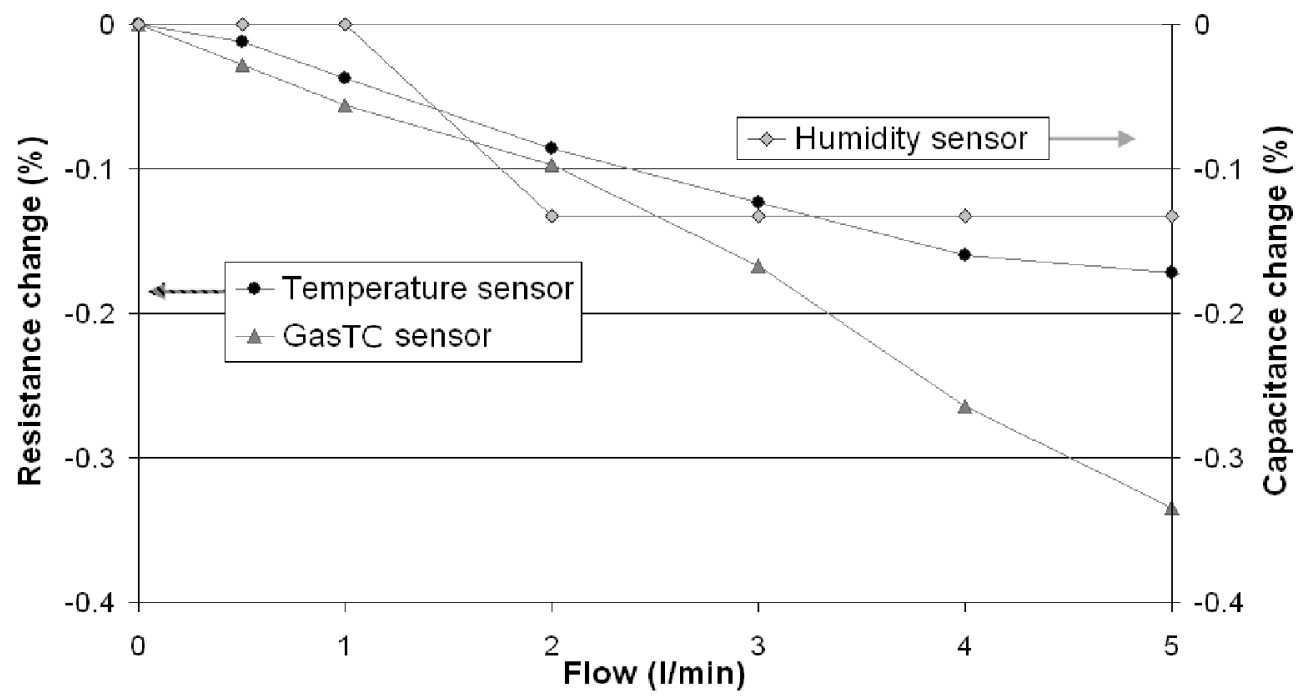

Due to the setup used to measure the resistance of the thermal conductivity sensor, a constant $100 \mathrm{~mA}$ current is flowing through it, increasing its temperature. The decrease in its resistance is then due to heat loss caused by forced convection, similar to that of the heater of the gas flow sensor. There is very good agreement between temperature changes resulting from experimental resistance variations and the hot-wire model given for the gas flow sensor constructed from [23] with: $A=-0.54$ and $B=0.905$.

\section{Wireless Multisensor Platform}

\subsection{Multi-MEMS Data-Logging Unit}

To meet the miniaturization requirements of a WSN system for monitoring the environmental conditions in the envisaged scenario (asset tracking), two multisensor chips with eight different MEMS sensors have been integrated on the highly modular programmable Tyndall 25 mote, where the "plug and play" stackable layers include communications capability and power conditioning. No CMOS circuitry has been integrated on this prototype sensor chip, although we have previously used similar processing to successfully fabricate CMOS-integrated MEMS devices and the CMOS compatibility of the process has been verified [33,34]. Instead on-board data processing available on the mote has been used. A serial memory layer has also been incorporated to complete the multi-functional 
environmental monitoring unit with data mining capabilities, compression, and storage for further transmission [8]. Sensor-specific signal conditioning circuitry has been designed to be interfaced with existing modules. User-defined onboard programming allows application-specific data sampling, treatment and cross-correlation compensation.

Figure 19. Topmost component of the Tyndall25 mote with two MEMS multisensor bare die.

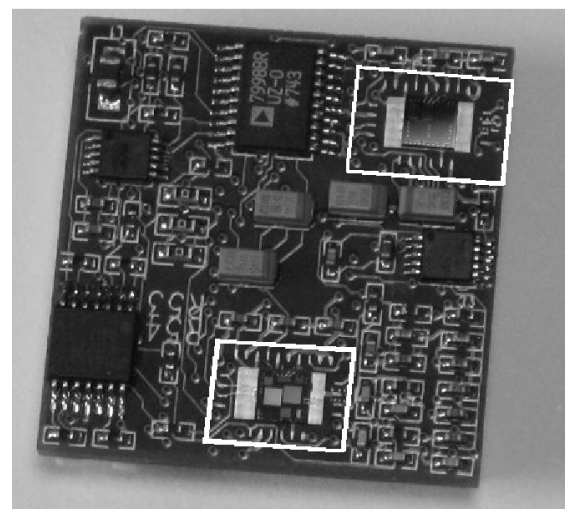

Under a 4V supply, the module has been successfully tested for simultaneous collection, recording, $\mathrm{RF}$ transmission and reading of sensor data. This continuous process required a total power consumption of $49 \mathrm{~mW}$. By decreasing data sampling rate, it is possible to further lower power consumption.

\section{Conclusions}

The novel CMOS-compatible MEMS process detailed in this paper has been used to integrate five different types of environmental sensors on a silicon substrate. To date, humidity, temperature, corrosion, gas thermal conductivity and gas flow sensors have been fabricated, although other sensor types compatible with our process are also feasible.

Characterization of sensor operation and cross-sensitivity has been carried out, and physical ageing of humidity sensors has also been investigated. It is believed that variations in measured parameters such as metal resistivity and polyimide diffusion coefficients may be due to the plasma etch steps used in the fabrication process.

Finally, this MEMS multisensor die has been integrated on board a miniaturized wireless sensor platform for environmental monitoring. This low-power WSN module incorporates both sensing redundancy and error compensation without increasing the need for real-estate onboard. Both real-time external communication data collection in a serial memory are available depending on the deployment scenario.

\section{Acknowledgements}

This work was funded by Science Foundation Ireland under the Centre for Telecommunications Value-Chain Research. The authors would like to warmly thank the staff at the Tyndall Central Fabrication Facility for device fabrication. 


\section{References}

1. Akyildiz, I.F.; Su, W.; Sankarasubramaniam, Y.; Cayirci, E. Wireless sensor networks: A survey. Comput. Netw. 2002, 38, 393-422.

2. Garcia-Sanchez, A.J.; Garcia-Sanchez, F.; Garcia-Haro, J. Wireless sensor network deployment for integrating video-surveillance and data-monitoring in precision agriculture over distributed crops. Comput. Electron. Agric. 2011, 75, 288-303.

3. Barton, J.; Hynes, G.; O’Flynn, B.; Aherne, K.; Norman, A.; Morrissey, A. 25 mm sensor-actuator layer: A miniature, highly adaptable interface layer. Sens. Actuat. A 2006, 132, 362-369.

4. Stankovic, J.A.; Wood, A.D.; He, T. Realistic Applications for Wireless Sensor Networks. In Theoretical Aspects of Distributed Computing in Sensor Networks Monographs in Theoretical Computer Science An EATCS Series; Springer-Verlag: Berlin, Heidelberg, Germany, 2011; Part 8, Chapter 25, pp. 835-863.

5. Harte, S.; O’Flynn, B.; Martínez-Catalá, R.V.; Popovici, E. Design and Implementation of a Miniaturised Low Power Wireless Sensor Node. In Proceedings of 18th European Conference on Circuit Theory and Design, Seville, Spain, 27-30 August 2007; pp. 894-897.

6. Xu, Z.; Koltsov, D.; Richardson, A.; Le, L.; Begbie, M. Design and Simulation of a Multi-Function MEMS Sensor for Health and Usage Monitoring. In Proceedings of Prognostics \& System Health Management Conference (PHM2010 Macau), Macao, China, 12-14 January 2010; pp. 1-7.

7. Bouchaud, J. Multisensor MEMS to Post Colossal Growth in 2010 and Beyond; iSupply Report 2010.

8. Hautefeuille, M.; O’Mahony, C.; O’Flynn, B.; Khalfi, K.; Peters, F. A MEMS-based wireless multisensor module for environmental monitoring. $J$. Microelectron. Reliab. 2008, 48, 906-910.

9. Touma, J.E.; Klausutis, T.J.; Fesseden, M.; New, C.; Diel, D.D. Precision Multi-Sensor Optical Navigation Test-Bed Utilizing Ground-Truthed Data Set. In Proceedings of IEEE/ION Position Location and Navigation Symposium (PLANS), Indian Wells, CA, USA, 4-6 May 2010; pp. 1237-1237.

10. Healy, T.; Donnelly, J.; O’Neill, B.; Alderman, J.; Mathewson, A. Silicon Fibre Technology Development for Wearable and Ambient Electronics Applications. In Frontiers in Electronics; Book World Scientific Publishing Co. Pte. Ltd.: Singapore, 2005; pp. 713-721.

11. Lee, C.Y.; Lee, G.B. Humidity sensors: A review. Sens. Lett. 2005, 3, 1-14.

12. Osterberg, P.M.; Senturia, S. MTEST: A test chip for MEMS material property measurement using electrostatically actuated test structures J. Microelectromech. Syst. 1997, 6, 107-118.

13. HD Microsystems. Available online: http://www.hdmicrosystems.com (accessed on 24 October 2011).

14. Denton, D.D.; Buncick, M.C.; Pranjoto, H. Effects of process history and aging on the properties of polyimide films. J. Mater. Res. 1991, 6, 2747-2754.

15. Denton, D.D.; Camou, J.B.; Senturia, S.D. Effects of Moisture Uptake on the Dielectric Permittivity of Polyimide Films. In Proceedings of the International Symposium on Moisture and Humidity, Washington, DC, USA, 15-18 April 1985; pp. 505-514. 
16. Crank, J. The Mathematics of Diffusion, 2nd Ed.; Oxford University Press: Oxford, UK, 1975.

17. Kim, S.H.; Moon, H.; Ahn, J. Effects of $\mathrm{SF}_{6}$ addition to $0_{2}$ plasma on polyimide etching in ECR plasma etcher. Jpn. J. Appl. Phys. 2000, 39, 7011-7012.

18. Dokmeci, M.; Najafi, K. A high-sensitivity polyimide capacitive relative humidity sensor for monitoring anodically bonded hermetic micropackages. J. Microelectromech. Syst. 2001, 10, 197-204.

19. Wu, S.Y.; Denton, D.D. Dielectric modelling of polyimide exposed to environmental stress. IEEE Trans. Electr. Insul. 1992, 27, 362-373.

20. Pethrick, R.A.; Hayward, D. Real time dielectric relaxation studies of dynamic polymeric systems. Prog. Polym. Sci. 2002, 27, 1983-2017.

21. Lide, D.R. Chemical Rubber Company Handbook of Chemistry and Physics, 76th ed.; CRC Press: Boca Raton, FL, USA, 1995.

22. Saxenat, V.K.; Saxenat, S.C. Measurement of the thermal conductivity of helium using a hot-wire type of thermal diffusion column. J. Phys. D: Appl. Phys. 1968, 1, 1341-1351.

23. Gustafsson, S.E.; Karawacki, E.; Khan, M.N. Transient hot-strip method for simultaneously measuring thermal conductivity and thermal diffusivity of solids and fluids. J. Phys. D: Appl. Phys. 1979, 12, 1411-1421.

24. Hautefeuille, M.; O’Flynn, B.; Peters, F.; O’Mahony, C. Miniaturised multi-MEMS sensor development. J. Microelectron. Reliab. 2009, 49, 621-626.

25. Elwenspoek, M. Thermal Flow Micro Sensors. In Proceedings of the 1999 International Semiconductor Conference CAS'99, Sinaia, Romania, 5-9 October 1999; Volume 2, pp. 423-435.

26. Hoge, C.E. Corrosion criteria for electronic packaging: Part I-III. IEEE Trans. Compon. Hybrids Manuf. Technol. 1990, 13, 1090-1109.

27. Seo, J.; Han, H. Water diffusion studies in polyimide thin films. J. Appl. Polym. Sci. 2001, 82, 731-737.

28. Lee, C.Y.; Lee, G.B. Micromachine-based humidity sensors with integrated temperature sensors for signal drift compensation. J. Micromech. Microeng. 2003, 13, 620-627.

29. Jason, C.; Wood, J.L. Some electrical effects of the adsorption of water vapour by anodized aluminium. Proc. Phys. Soc. Sect. B 1955, 68, 1105-1116.

30. De Freitas, C.R.; Littlejohn, R.N. Cave climate: Assessment of Heat and moisture exchange. $J$. Climatol. 1987, 7, 553-569.

31. Verdaguer, A.; Weis, C.; Oncins, G.; Ketteler, G.; Bluhm, H.; Salmeron, M. Growth and structure of water on $\mathrm{SiO}_{2}$ films on $\mathrm{Si}$ investigated by kelvin probe microscopy and in situ $\mathrm{X}$-ray spectroscopies. Langmuir 2007, 23, 9699-9703.

32. Schmitt, G.; Schultze, J.W.; Fassbender, F.; Buss, G.; Luth, H.; Schöning, M.J. Passivation and corrosion of microelectrode arrays. Electrochim. Acta 1999, 44, 3865-3883.

33. Robles, S.; Yieh, E.; Nguyen, B.C. Moisture resistance of plasma enhanced chemical vapor deposited oxides used for ultralarge scale integrated device applications. J. Electrochem. Soc. 1995, 142, 580-585.

34. Hill, M. Micromachined CMOS Compatible Tunable Capacitors. Ph.D. Thesis, National University of Ireland, Cork, Ireland, 2007. 
35. Lambkin, P.; Lane, B.; O’Heifearnan, I.; Gillham, J.; Eatton, R. Characterisation of CMOS Compatible Uncooled Microbolometers. In Proceedings of the 2000 IEEE/LEOS International Conference on Optical MEMS, Kauai, HI, USA, 21-24 August 2000; pp. 99-100.

(C) 2011 by the authors; licensee MDPI, Basel, Switzerland. This article is an open access article distributed under the terms and conditions of the Creative Commons Attribution license (http://creativecommons.org/licenses/by/3.0/). 